\title{
Training and Adolescent Adjustment among Academically Gifted European and Chinese American Students
}

\author{
Tzu-Fen Chang ${ }^{1, *}$, Desiree B. Qin ${ }^{2}$ \\ ${ }^{1}$ Department of Human Environmental Studies, Central Michigan University, United States \\ ${ }^{2}$ Department of Human Development \& Family Studies, Michigan State University, United States
}

Copyright $\bigcirc 2017$ by authors, all rights reserved. Authors agree that this article remains permanently open access under the terms of the Creative Commons Attribution License 4.0 International License

\begin{abstract}
Training (jiao xun) has been proposed as an indigenous form of Chinese parenting. Does it exist in other populations? If so, how might it be associated with developmental outcomes? We examined the relationships of training to adolescent academic, psychological, and school adjustment in a sample of 214 Chinese American and 125 European American academically gifted students. We found that training also occurs in European American families with academically gifted children. There were other ethnic similarities: Training was not associated with depression or anxiety in either group, and it was a positive predictor of academic efficacy for both groups. One difference emerged: Training was not associated with school-engagement problems for the European American students, but it was positively associated with fewer school-engagement problems for the Chinese American students. The findings suggest that training has positive implications for academic and school adjustment among academically gifted Chinese American adolescents and for academic adjustment only among their European American peers.
\end{abstract}

Keywords Adolescent Adjustment, Parenting, Chinese Americans, European Americans, Academically Gifted Students

\section{Introduction}

Jiao xun, which literally translates as training and has been proposed as an indigenous form of Chinese parenting, means that parents use continuous control to educate children to achieve societal and parental expectations, such as educational success and proper conduct [1]. In addition to the controlling component, training parenting also conveys parental nurturance and warmth through parents' instrumental support, devotion, and guidance for children's education and behavior [1]. In 2011, Amy Chua [2] published her highly contested book Battle Hymn of the Tiger Mother, detailing how she exercised such training approach in parenting her academically gifted daughters. For example, she forbade them to attend sleepovers or camps and continuously and devotedly provided them with study guidance, in order to train them to be highly successful in their educational endeavors. Although training parenting has been framed as "Chinese parenting," Chua argues that this parenting style does not occur only in Chinese families; there are "some Korean, Indian, Jamaican, Irish, and Ghanaian parents who qualify too" (p. 4). While there is some emerging scholarly work on this Chinese parenting style (e.g., [3]), little empirical research has investigated whether aspects of this approach occur among parents from other ethnic backgrounds - including the parents of academically gifted students - and if so, how these might be associated with children's developmental outcomes.

In cross-cultural parenting research, researchers often test Western constructs on non-Western populations. For example, Baumrind's parenting typology has been well studied for Chinese/Chinese American families (e.g., [4, 5]). While this approach provides useful information on cross-cultural differences, its overemphasis on Western constructs eclipses constructs that may be more salient in other cultures but also exist in Western cultures. For example, parent-child relationship harmony has been identified as an important Chinese cultural value [6]. However, relationship harmony is also important in Western cultures [7]. Further, Eastern and Western parenting approaches have often been pitted against each other with polarized concepts. For example, European American parents have been described as placing less emphasis on controlling parenting, partly due to socialization goals that center on fostering children's autonomy, while Asian (including Chinese) parents tend to be more controlling because they emphasize relatedness in child socialization [8]. However, Tamis-LeMonda and 
colleagues [7] argue that this view does not capture the complete picture of European American (or Asian American) parenting. Controlling parenting approaches may also occur in European American families. Tamis-LeMonda and colleagues further argue that potential cross-ethnic similarities in the approach to parenting are often underestimated and overlooked.

Guided by these perspectives, this study examines the training approach to parenting in a group of academically gifted European American and Chinese American students to investigate whether the two groups of students report similar levels of training at home and whether training has similar implications for the two groups regarding adolescent academic and psychological adjustment and school engagement. Academically gifted children are those who "exhibit outstanding intellectual ability, or promise, and are capable of extraordinary performance and accomplishment" [9, page 59]. Common approaches to identification of academically gifted students include utilizing single or multiple IQ or achievement test scores [9]. In this study, the high school from which the sample of academically gifted students was drawn adopted a single test score (the Specialized High School Admission Test) to screen and select academically gifted students.

The reasoning behind targeting a sample of academically gifted adolescents is as follows. Research on parenting and child adjustment tends to focus on at-risk students [10]. Academically gifted children are generally perceived as being at low risk for problems in academic and psychological adjustment and thus as having less need for intervention. As a result, research on these children is limited. However, academic talent does not necessarily assure positive adjustment. For example, although research has found that some academically gifted students have a high level of academic efficacy (i.e., beliefs and perceptions that they have the capacity to enact multiple actions to achieve various types of academic success, such as demonstrating intelligence and finding answers)[11], others have relatively low efficacy [12]. Regarding psychological adjustment and school engagement (e.g., getting along with teachers and peers, paying attention in class), research has found that some academically gifted students adjust relatively well-for example, they report good school engagement and low levels of depression and anxiety, while in contrast, others adjust relatively poorly - for example, they report more school engagement problems and high levels of depression and anxiety $[13,14]$. Further, previous research indicates that parenting approaches/styles play an important role in explaining variations in academic and psychological adjustment and school engagement among academically gifted students (see the review of [15]). For example, academically gifted students tend to have strong academic performance and efficacy as well as school engagement when their parents exercise a parenting style that emphasizes both responsiveness and control (i.e., authoritative parenting)[16], and they report low levels of anxiety and better skills for coping with psychological problems when they come from families with high levels of parental warmth [13]. Thus, examining parenting and adolescent adjustment in this population can inform our efforts to design effective interventions to support the positive adjustment of students with different academic backgrounds. This study investigates the extent of training at home and its implications for academic efficacy, school engagement, depression, and anxiety among academically gifted European and Chinese American adolescents. The study targets these adolescent outcomes because research has indicated significant variations in the levels of these outcomes among academically gifted students $[12,13]$.

\subsection{Parenting}

\subsubsection{Parenting Style}

Parenting research has been strongly influenced by Baumrind's [17] typology, which identifies two key components of parenting: parental responsiveness (the amount of nurturance, warmth, and responses to children's needs that parents provide) and parental control (the degree to which parents exert firm control and demand mature behavior from their children). These two components determine four parenting styles: authoritative (high in both components), authoritarian (low in responsiveness but high in control), permissive (high in responsiveness but low in control), and indifferent (low in both components). Based on research on both regular and gifted (including academically gifted) students, findings for European American children consistently suggest that an authoritative style benefits the children's overall development, including academic [4, 18], psychological [3], and social [19,20] adjustment and school engagement [21] (also see the reviews of $[8,15]$ ).

However, research findings for Chinese children and adolescents do not consistently show that an authoritative parenting style has positive implications for their development, especially regarding academic adjustment. For example, although some studies indicate that the academic performance of Chinese elementary schoolers and adolescents is positively associated with authoritative parenting but negatively associated with authoritarian parenting [22, 23], other studies have found that the academic adjustment of Chinese/Chinese American preschoolers and adolescents (e.g., academic performance and effort) is positively associated with authoritarian [5, 24] rather than authoritative [4] parenting styles. These quantitative research studies were based on samples with regular students only or with both regular and academically gifted students; to our knowledge, similar research that specifically examines academically gifted Chinese/Chinese American students is lacking. Nevertheless, although the overall findings are mixed, these specific findings that an authoritarian style is positively linked with good developmental outcomes, based on samples with both regular and academically gifted students, suggest that 
authoritarian parenting may have positive implications for the development of both regular and academically gifted ethnic Chinese children and adolescents, especially regarding academic outcomes.

However, Chao [4] argues that instead of authoritarian parenting, which carries negative connotations, concepts such as jiao xun may characterize Chinese parenting more accurately by highlighting positive aspects of control. Jiao xun, which literally translates as training, refers to parents' continuous control of their children for the purpose of teaching them to meet societal and parental expectations (e.g., educational achievement and proper conduct). In addition to the controlling component, another key component of parenting-i.e., parental responsiveness (including parental nurturance, warmth, and responses) - also exists in training parenting. Specifically, parental responsiveness is expressed in training through parents' instrumental support, devotion, and guidance for children's education and behavior [4]. Jiao xun is derived from the traditional Chinese parenting concept of guan (to govern), defined as firm parental governance and control in child socialization. Another related but distinct aspect of Chinese parenting is jiao, "parental expectations and advice on culturally specific social propriety, e.g., respecting older adults" [25, page 322$]$.

Training, guan, and jiao all originated from Confucian-defined parental responsibilities to discipline children [26]. Chao [27] argues that training may overlap with authoritarian parenting to some extent, but that these styles are also distinct from each other. Although both stress parents' firm control and demands for their children's correct conduct and behavior, there are two important distinctions between the two styles. First, although both styles include parental control, they differ in how it is conceptualized and expressed. In Baumrind's typology, parental control is conceptualized as an expression of parents' hostility toward or dominance of children, while in training, parental control carries a positive connotation of continuous monitoring and guidance of children [27] — which can be beneficial for children's academic adjustment [3] and school engagement [28]. Second, authoritarian parenting does not convey parental responsiveness, while parental responsiveness is expressed in training through instrumental support, devotion, and guidance for children's education and behavior. The expression of parental responsiveness through instrumental support and devotion in training is also different from parental responsiveness in authoritative parenting, which emphasizes physical acts (e.g., kissing and hugging) or emotional expressions (e.g., praise) [29].

Because training is a culturally embedded parenting style for Chinese parents, they may use training more than parents from other ethnic/cultural backgrounds, such as European American parents. Indeed, some studies have found that immigrant Chinese American parents endorse training to a greater degree than do European American parents [28, 30]. However, Li et al.'s [3] study found no ethnic difference, but rather that mainland Chinese and European American college students perceived similar levels of training. Li et al. suggest that training parenting may also occur in European American families. These findings were based on samples with only regular students; to our knowledge, research that examines levels of training specifically among academically gifted Chinese/Chinese American and European American students is lacking.

\subsubsection{Training and Child Adjustment}

Much research has been devoted to understanding the implications of different Western parenting styles on children's developmental outcomes (e.g., [31, 32]). Yet only a few studies have been conducted to understand the implications of non-Western parenting constructs-such as training - for child developmental outcomes. For example, regarding training's implications for academic adjustment, studies of mainland and Hong Kong Chinese college students have found positive associations of training with academic performance and efficacy [3, 33]. Positive implications of training for school engagement among Chinese/Chinese American students have also emerged, including a positive link between paternal training during children's preschool years and fewer problem behaviors (including school-engagement problems) four years later for second-generation Chinese Americans [28] and indirect positive effects of both maternal and paternal guan on mainland Chinese adolescents' school engagement via the mediation of the children's xiao (filial piety)[25]. However, some studies on mainland and Hong Kong Chinese adolescents have found no association of training with their academic performance and school engagement [34, 35]. These mixed findings may be related to age- for example, positive implications of training for academic adjustment and school engagement may be less likely for ethnic Chinese adolescents than for their younger or older counterparts. However, this surmise cannot be tested since a large body of studies at each developmental stage that allows comparison across stages is lacking.

Two of the studies mentioned above [3,28] also studied European American peers and found that for these students, training was not associated with academic adjustment and school engagement. Moreover, these two studies suggested that positive implications of training for academic adjustment and school engagement may be more likely for Chinese/Chinese Americans, but not for European Americans.

Regarding psychological adjustment, the findings are somewhat mixed for Chinese/Chinese American students. Some suggest that training does not affect their psychological adjustment. For example, prior research has found no association of maternal/paternal training or guan with depression, self-esteem, or life stress in samples of mainland Chinese college students [3], mainland Chinese adolescents [35], and second-generation Chinese American preschoolers/kindergarteners [28]. Other studies have found positive associations between training or guan and positive 
psychological adjustment. For example, in a sample of adolescent mainland Chinese girls, Wang [25] found that maternal guan predicted less depression via the mediation of their xiao. Stewart, Bond, Kennard, Ho, and Zaman [36] found that both maternal and paternal training predicted higher life satisfaction for female Hong Kong Chinese college students. These mixed findings may be related to age-for example, positive implications of training for psychological adjustment may be more likely for ethnic Chinese adolescents and college students than their younger counterparts. Again, however, this surmise cannot be tested since there does not exist a large body of studies at each developmental stage that would allow comparison across stages.

Three of the studies mentioned in the previous paragraph $[3,28,36]$ also examined European American peers and in this case found no associations between training and psychological adjustment (i.e., depression, self-esteem, and life stress). Moreover, Stewart et al. [36] suggested that positive implications of training for psychological adjustment (as indicated by life satisfaction) may be more likely for Chinese students, but not for European Americans.

Regarding the previously mentioned quantitative studies that examine the implications of training, Huntsinger and Jose [28], Li et al. [3], and Stewart et al. [36] used samples of regular students, while the rest used samples with a mix of both regular and academically gifted students. To our knowledge, similar research that examines implications of training for developmental outcomes specifically among academic gifted Chinese, Chinese American, and European American students is lacking.

\subsection{The Present Study and Hypotheses}

We note at least two gaps in the prior research on training parenting. First, most studies have compared non-immigrant Chinese students (in mainland China or Hong Kong) with their European American peers, and a large number of these have noted that positive implications of training for academic and psychological adjustment and school engagement may be more likely for Chinese, but not for European American students. However, few studies have compared immigrant Chinese (e.g., Chinese American) students with their European American peers regarding implications of training for child adjustment outcomes. Such research would have the potential to help understand whether positive implications of training continue to exist among immigrant Chinese students and remain more likely for them compared to their European American peers, since training is an indigenous form of Chinese parenting. Second, as previously mentioned, research on the implications of training for child adjustment outcomes that specifically examines academically gifted European and Chinese American students is lacking. A study of these students could address whether training might have similar implications for the adolescent development of European and Chinese American academically gifted students, given that academic success is likely to be highly valued by both European and Chinese American academically gifted students and their parents [37] and that training serves the purpose of teaching children to meet societal and parental expectations (e.g., educational achievement) [1]. To address these gaps, we examine the relation between training and adolescents' academic and psychological adjustment and school engagement in a sample of academically gifted European and Chinese American adolescents.

This study has two goals: (a) to investigate differences in academically gifted European and Chinese American high school students' perceived levels of training, and (b) to investigate differences between the two groups regarding associations of training with academic efficacy, psychological adjustment (depression and anxiety), and school engagement. Since, as previously mentioned, academic success is likely to be highly valued by academically gifted students and their parents in both ethnic groups [37] and training aims to help children achieve educational success [1], parents of European American academically gifted students might also use training. However, considering that training is an indigenous form of Chinese parenting and that ethnic Chinese (e.g., Chinese American) children may be more likely to appreciate training's positive connotations (e.g., parental devotion and guidance)[1] , we hypothesize that 1) training levels will be higher for Chinese American adolescents than for European American adolescents, and 2) the positive associations of training with academic efficacy, positive psychological adjustment (low levels of depression and anxiety), and fewer school-engagement problems will be stronger for Chinese American adolescents than for European American adolescents.

\section{Methods}

\subsection{Procedure}

Our study uses data from a longitudinal project on the psychosocial development of academically gifted students. Participants were academically gifted students who were recruited from a highly selective public high school in a northeastern U.S. metropolis that is operated by the city's board of education to provide education for academically gifted students. Students' admission is determined solely by the Specialized High School Admission Test [39], and the school eventually enrolls fewer than $5 \%$ of the students who take the test. The entire ninth-grade cohort was invited to participate $(N=825)$. The principal investigator gave a presentation about the study to parents of the ninth-grade cohort at a parent association meeting and in first-year English classes. Parental consent forms were distributed to all first-year students in English classes. During a 40-minute session of an English class, 745 students who returned the 
consent forms ( $90 \%$ of the cohort) filled out the survey. Of the original sample, 576 students $(77.3 \%)$ participated in the 2008-2009 follow-up data collection when they were juniors.

\subsection{Sample}

Given that the training scale was only administered in the follow-up data collection, this study focused on the subsample of students who participated in the follow-up study. Of these students, we excluded 47 (8.2\%) who completed less than $5 \%$ of the survey. Among the remaining 529 students, $40.5 \%$ were self-identified as Chinese American, 26.7\% as having other Asian backgrounds (e.g., Korean, Indian), 23.6\% as European American, and $8.9 \%$ as other ethnicities (predominantly Black and Latino groups). This trend of Asian-student domination in our sample is reflected in the larger sample at the time of the first data collection, with $63 \%$ of the first-year class being Asian, $31 \%$ European American, and 6\% having other ethnicities.

Our final sample consisted of 214 Chinese American ( $19.1 \%$ first generation, $79.4 \%$ second generation, and $0.9 \%$ third generation or beyond, with $0.5 \%$ not reporting) and 125 European American students (20.8\% first generation, $28.8 \%$ second generation, $46.4 \%$ third generation or beyond, with $4 \%$ not reporting). Most of the first-generation Chinese American adolescents and their parents (95\%) and also the parents of second- and later generation Chinese adolescents (84\%) came from mainland China, and the rest came from Taiwan, Hong Kong, or other Asian countries. The mean age for the sample in the ninth grade was $14.49(S D=0.53)$. The gender distribution was almost even for Chinese Americans (50.5\% were males), while the majority of the European Americans were male (62.4\%). For both ethnic groups, the majority lived in a nuclear family $(86.9 \%$ of the Chinese Americans and 76.8\% of the European Americans). Eligibility for free school lunches served as a proxy for socioeconomic status (SES). Here we noted a marked ethnic difference: While only $6.4 \%$ of the European American students qualified for free or reduced-price lunch, $51.2 \%$ of the Chinese American students qualified.

\subsection{Measures}

\subsubsection{Measurement Invariance Test}

We used Mplus 7.0 [39] to conduct exploratory factor analyses (EFAs) and multiple-group confirmatory factor analyses (CFAs) to test whether the measurement constructs for the measures of training, depression, anxiety, school-engagement problems, and academic efficacy were invariant between the European and Chinese American samples. The EFA results indicate that each of the measures had one similar overarching factor across both groups, suggesting the existence of at least configural invariance across the groups.

Using Chen, Sousa, and West's [40] procedure, we further conducted multiple-group CFAs to test equivalence in item loadings and thresholds across the groups. The CFA results showed that training and school-engagement problems were strongly invariant (i.e., equivalent item loadings and thresholds), while all the other measures were partially strongly invariant (i.e., equivalent item loadings across the two groups, with the thresholds for scale points in some items relaxed to be different for the two groups; see Table 1). According to Chen et al. [40], the results are acceptable because, with the exception of training, this study did not compare the two groups in terms of means for the measures of adolescent outcomes but rather in terms of the associations of the adolescent outcomes with training. Weak invariance (i.e., equivalent item loadings) serves as a sufficient condition for doing this. Additionally, since strong invariance is a sufficient condition for comparing means of measures across groups, it was acceptable to compare the two groups in terms of means for training. All measures discussed in this section were assessed at the second wave and were reported by students.

\subsubsection{Training}

Chao's training scale [1] includes a six-item subscale for ideologies about child development and learning and a seven-item subscale for ideologies about the parent-child relationship. In this study, training was measured using the first subscale. The second subscale was not used because many items in that subscale (e.g., "Children should be allowed to sleep in parent's bed") were considered less developmentally appropriate for this sample or were focused on children's attitudes toward filial piety rather than on parenting, and this study was not focused on children's attitudes but rather on parenting. One example item used is "Parents must begin training children as soon as they are ready." Participants rated how strongly their parents would agree with each item on a 5-point scale $(0=$ strongly disagree to $4=$ strongly agree). Prior estimates of the reliability of Chao's scale have been adequate for older children, including adolescents $(\alpha=.72 ;[34])$. We assessed the adolescents' reports on training parenting because this approach has been widely used in previous research on older children, including adolescents (e.g., $[25,35])$ and some research notes high levels of consistency between adolescent and parent report data in family dynamics [41].According to Chen et al. (2005), unequal loadings of items on their underlying factor across groups indicate that the measurement units for the factor are not identical across groups. Thus, the CFA result excluded one item with different loadings for the two groups. 
Table 1. Measures of Fit for All the Primary Variables for Multiple-Group Confirmatory Factor Analyses Across Ethnicities

\begin{tabular}{|c|c|c|c|c|}
\hline Variable & $\begin{array}{l}\text { Configural } \\
\text { Invariance }\end{array}$ & Weak Invariance & Strong Invariance & Partially strong Invariance \\
\hline \multicolumn{5}{|l|}{ Training } \\
\hline Chi-square & 24.57 & 29.45 & 47.89 & - \\
\hline$d f$ & 10 & 14 & 34 & - \\
\hline CFI & .954 & .951 & .956 & - \\
\hline RMSEA & .08 & .08 & .05 & - \\
\hline$\Delta$ Chi-square $(\Delta d f)$ & & $6.81(4)$ & $22.53(20)$ & - \\
\hline \multicolumn{5}{|l|}{ Depression } \\
\hline Chi-square & 382.55 & 386.20 & 513.15 & 403.80 \\
\hline$d f$ & 270 & 287 & 323 & 302 \\
\hline CFI & .953 & .958 & .920 & .957 \\
\hline RMSEA & .05 & .05 & .06 & .05 \\
\hline$\Delta$ Chi-square $(\Delta d f)$ & & $22.47(17)$ & $143.27 * * *(36)$ & $41.52(32)$ \\
\hline \multicolumn{5}{|l|}{ Anxiety } \\
\hline Chi-square & 531.39 & 516.71 & 781.46 & 527.79 \\
\hline$d f$ & 378 & 398 & 421 & 404 \\
\hline CFI & .951 & .962 & .885 & .960 \\
\hline RMSEA & .05 & .04 & .07 & .043 \\
\hline$\Delta$ Chi-square $(\Delta d f)$ & & $21.15(20)$ & $276.40 * * *(23)$ & $29.38(26)$ \\
\hline \multicolumn{5}{|c|}{ School Engagement Problems } \\
\hline Chi-square & .00 & 2.03 & 17.86 & - \\
\hline$d f$ & 0 & 2 & 14 & - \\
\hline CFI & 1.000 & 1.000 & .991 & - \\
\hline RMSEA & .00 & .01 & .04 & - \\
\hline$\Delta$ Chi-square $(\Delta d f)$ & & $2.59(2)$ & $16.12(12)$ & - \\
\hline \multicolumn{5}{|l|}{ Academic Efficacy } \\
\hline Chi-square & .00 & 5.07 & 20.03 & 5.83 \\
\hline$d f$ & 0 & 2 & 5 & 4 \\
\hline CFI & 1.000 & .988 & .942 & .993 \\
\hline RMSEA & .00 & .10 & .14 & .05 \\
\hline$\Delta$ Chi-square $(\Delta d f)$ & & $5.07(2)$ & $14.92 * *(3)$ & $5.83(4)$ \\
\hline
\end{tabular}

Note. No fit indexes are reported for partially strong invariance for the variables of training and school-engagement problems because strong invariance was achieved for the two variables. The fit indices for training's configural invariance model were considered adequate for the following reason [58]. First, the value of CFI was $\geq .95$. Second, although the value of RMSEA was not $\leq .07$, its $90 \%$ CI was between .035 and .129 (which includes .05 ) and the null hypothesis that the population RMSEA was $\leq .05$ was retained $\left(p=.112\right.$, one-tailed). ${ }^{* *} p<.01 ; * * * p<.001$ (two-tailed tests).

Table 2. Means, Standard Deviations, and Cronbach's Alphas for the Ethnic Groups

\begin{tabular}{|c|c|c|c|c|c|c|c|c|c|c|c|c|c|}
\hline \multirow[t]{2}{*}{ Variables } & \multicolumn{3}{|c|}{ Overall Sample } & \multicolumn{5}{|c|}{ European Americans } & \multicolumn{5}{|c|}{ Chinese Americans } \\
\hline & $M$ & $S D$ & $\alpha$ & $M$ & $S D$ & $\alpha$ & Range & $n$ & $M$ & $S D$ & $\alpha$ & Range & $n$ \\
\hline Training & 2.45 & 0.60 & .62 & 2.50 & 0.63 & .67 & $0.80-4.00$ & 123 & 2.43 & 0.57 & .62 & $0.00-4.00$ & 214 \\
\hline Depression & 0.65 & 0.25 & .73 & 0.58 & 0.24 & .75 & $0.22-1.28$ & 125 & 0.70 & 0.24 & .70 & $0.24-1.44$ & 213 \\
\hline Anxiety & .41 & 0.24 & .88 & 0.33 & 0.25 & .90 & $0.00-0.95$ & 125 & 0.46 & 0.22 & .85 & $0.05-0.95$ & 213 \\
\hline $\begin{array}{c}\text { School- } \\
\text { Engagement Problems }\end{array}$ & 1.13 & 0.82 & .74 & 1.18 & 0.78 & .73 & $0.00-4.00$ & 119 & 1.10 & 0.85 & .74 & $0.00-4.00$ & 205 \\
\hline Academic Efficacy & 4.63 & 1.18 & .75 & 4.55 & 1.24 & .77 & $0.67-6.00$ & 116 & 4.67 & 1.15 & .75 & $0.67-6.00$ & 206 \\
\hline
\end{tabular}

Note. For all of the adolescent outcomes, the percentages of the overall sample reporting high levels of positive psychological and academic adjustment and school engagement were low. Specifically, $18.04 \%$ of the sample on average reported a low level of depression (1SD below the mean), while the rest reported average or high levels of depression; $14.48 \%$ of the sample on average reported a low level of anxiety (1SD below the mean), while the rest reported average or high levels of anxiety; $15.26 \%$ of the sample on average reported a low level of school-engagement problems (ISD below the mean), while the rest reported average or high levels of the problems; and $10.81 \%$ of the sample on average reported a high level of academic efficacy (ISD above the mean), while the rest reported average or low levels of academic efficacy. 
Table 3. Partial and Zero-order Correlations of Training with the Variables of Adolescent Adjustment

\begin{tabular}{|c|c|c|c|c|}
\hline \multirow{2}{*}{ Variables } & \multicolumn{2}{|c|}{$\begin{array}{c}\text { Chinese Americans } \\
(\mathrm{N}=214)\end{array}$} & \multicolumn{2}{c|}{ European Americans (N=125) } \\
\hline & Partial Correlations & $\begin{array}{c}\text { Zero-Order } \\
\text { Correlations }\end{array}$ & Partial Correlations & $\begin{array}{c}\text { Zero-Order } \\
\text { Correlations }\end{array}$ \\
\hline Depression & -.05 & -.04 & -.07 & -.06 \\
\hline Anxiety & .01 & .02 & .13 & .13 \\
\hline School-Engagement Problems & $-.17^{*}$ & $-.17 *$ & .03 & .02 \\
\hline Academic Efficacy & $.38^{* * *}$ & $.36^{* * *}$ & $.43^{* * *}$ & $.44^{* * *}$ \\
\hline
\end{tabular}

Note. We compared zero-order- and partial-correlation results for both groups, and found no substantial differences for either group. ${ }^{*} p<.05$;*** $p<.001$ (two-tailed tests).

For all of the scales discussed in this section (i.e., training, depression, anxiety, school-engagement problems, and academic efficacy), Cronbach's alpha was considered adequate for both ethnic groups and the overall sample, with the exception of training for the Chinese American participants and for the overall sample, which was not very strong in both cases $(\alpha=.62$; see Table 2$)$. Albeit with somewhat lower internal consistency, some evidence of construct validity for training for both groups emerged. There was evidence of configural invariance across the two groups and acceptable fit indices for the configural invariance model (see note in Table 1), which suggests adequate scale homogeneity and the model fit of factor structure are two of the important indicators for construct validity [42]. Additionally, concurrent validity was indicated by significantly positive correlations with good academic adjustment (i.e., academic efficacy) for both the European and the Chinese American samples (see results of zero-order correlations in Table 3). Finally, although there is some disagreement regarding which level of internal consistency is considered acceptable (e.g., [43]), a reliability of .60 or above has been established as acceptable [44]. We averaged the item scores for each scale in this section for further analysis.

\subsubsection{Depression}

We used Kovacs's [45] 27-item Child Depression Inventory to assess depressive symptoms such as sadness, pessimism, negative mood, and social isolation. Responses were given on a 3-point Likert-type scale. Prior research on adolescents from various ethnic groups has reported the high reliability of this scale (e.g., $\alpha=.80-.86$ )[46, 47]. The CFA result excluded nine items.

\subsubsection{Anxiety}

The anxiety scale was embedded in Reynolds and Richmond's [48] Revised Children's Manifest Anxiety Inventory. The scale contains 28 dichotomous items $(0=n o$, $1=$ yes), e.g., "I have trouble making up my mind." Prior research on large adolescent samples of diverse ethnicities indicate that this scale has high reliability (e.g., $\alpha=.85-.86$ ) and concurrent validity with social anxiety and depression $[49,50]$. The CFA result excluded seven items.

\subsubsection{School-Engagement Problems}

To measure school-engagement problems, we used four items from the "academics and education" section of the Add Health project codebook [51]. Students were asked to rate how often they had trouble in school engagement, such as "getting along with your teachers," "paying attention in school," or "getting along with other students" on a 5-point scale $(0=$ never to $4=$ every day). Prior research using large adolescent samples of diverse ethnicities has reported adequate reliability for this scale (e.g., $\alpha=.73-.83)[52,53]$. The CFA result excluded one item.

\subsubsection{Academic Efficacy}

Three items were created to measure adolescent perception of academic efficacy, e.g., "I expect to do well in school, such as in terms of homework and tests." A 7-point Likert scale $(0=$ not at all true of me to $6=$ very true of me $)$ was used. This measure had adequate internal consistency (see Table 2) and concurrent validity with good school adjustment (as indicated by negative correlations with school-engagement problems, $r(212 ; 123)=-.20$ and -.21 , $p s=.003$ and .022 (two-tailed) for the Chinese and European American samples, respectively).

\section{Results}

\subsection{Descriptive Statistics and Analysis Approaches}

Means and standard deviations for all of the primary variables appear in Table 2 . These variables were assumed to be normally distributed, given that the skewness coefficients were between -1.0 and 1.0 and the kurtosis coefficients between -1.0 and 2.0 for both groups and the overall sample [54]. Additionally, the measures of variability (SDs and ranges) indicate that there was variation (ranging from low to high) in the levels of all outcome variables (depression, anxiety, school-engagement problems, and academic efficacy) for each group (Table 2). Furthermore, our results indicate that while some of the sample reported high levels of positive psychological and academic adjustment and school engagement, the rest reported average/low levels of these, across both groups (see the note in Table 2). Although research on recent immigrant groups (e.g., Chinese 
Americans) suggests that the implications of parenting for child outcomes may be different for the first generation and the second- or later generations (e.g., [1]), we did not analyze the results for the first-generation and the second- or later generation Chinese American and European American students separately in our study because the preliminary analyses indicate for both ethnic groups no significant differences in mean levels between the two generational subgroups for any of the primary variables.

Missing data points for variables ranged from $0 \%$ to $5.02 \%$. Since the missing pattern of our study sample was not monotone, we used SPSS 19 to impute the missing data according to a multivariate normal model using the Markov Chain Monte Carlo estimation [55]. We produced five imputed data sets. Convergence was reached in each data set, and iterations between imputations were sufficient to make autocorrelations close to 0 . Imputed-data-based results are presented in the next subsection and in Table 3. We compared results based on listwise deletion and multiple imputation techniques and found no substantial differences.

\subsection{Ethnic Difference in Training}

Unexpectedly, we found no difference between European and Chinese American adolescents regarding perceived levels of training, $t(335)=.88, p=.380$ (two-tailed), and Cohen's $d$-metric effect size $(d=.10)$ was considered small. To investigate whether ethnic similarity was retained when the participants' demographic backgrounds were controlled, we tested a regression model in which training was regressed on ethnicity $(0=$ European American; $1=$ Chinese American $)$ and effect-coded covariates, including gender $(-1=$ male; $1=$ female), generational status $(-1=$ second or later generation; 1 = first generation), lunch status (a proxy for SES; two effect-coded variables: first, $-1=$ free, $0=$ reduced-price, $1=$ full price, and second, $0=$ free, $-1=$ reduced-price, $1=$ full price $)$, and family composition $(-1=$ nuclear family; $1=$ other [including single-parent household or not living with parents]). The finding indicates no ethnic effect on perceived levels of training, $\beta=-.03, p=.578$ (two-tailed). Therefore, the hypothesis that Chinese American students would perceive higher levels of training than the European American students was not supported. Further, one-sample $t$-tests were conducted for both groups to examine whether the levels of perceived training for each group were larger than the midpoint (2) of the training scale. The results indicate that the mean level for each group was significantly larger than $2, t \mathrm{~s}(122.05 ; 213)=8.55$ and $11.01, p \mathrm{~s}$ $<.001$ (one-tailed) ${ }^{1}$ for the European and Chinese American students, respectively, and both effect-size estimates were considered to be approaching large, $d \mathrm{~s}=.77$ and .75 , respectively. Together, the results suggest that the students in both groups perceived similarly high levels of training. ${ }^{1}$

\subsection{Correlation Results}

To examine the correlations of training with each of the adolescent outcome variables separately for the two groups, we estimated partial correlation coefficients, that is, the coefficients partialled out all the covariates mentioned in the previous section.

As shown in Table 3, a significantly positive partial correlation between training and academic efficacy emerged for both groups. A significantly negative partial correlation between training and school-engagement problems emerged only for the Chinese American participants. In terms of training and psychological adjustment, no significant partial correlations were found for either group.

Next, we investigated whether there were ethnic differences in terms of partial correlations of training with academic efficacy and school-engagement problems in order to test the study hypothesis that the positive associations of training with good academic adjustment and fewer school-engagement problems will be stronger for Chinese American adolescents than for European American adolescents. The test of ethnic differences was not conducted for depression and anxiety because there were no significant correlations of these with training for either ethnic group.

Additionally, it is important, for both ethnic groups, to detect violations of variance homogeneity with respect to their sampling distribution of partial correlations of training with academic efficacy and with school-engagement problems separately, because such violations may produce biased estimations of group differences in partial correlations of training with the two adolescent outcomes [56]. Considering the unbalanced sample sizes for the two ethnic groups, we used Aguinis et al.'s [56] ALTMMR computer program to perform $M$ tests [57] to test the assumption of homogeneous variances across the two groups for partial correlations of training with academic efficacy and with school-engagement problems. The assumption was retained for both adolescent outcomes. Thus, no adjustment was needed in estimations of group differences in partial correlations of training with the two adolescent outcomes. The findings indicate that the relationships between training and academic efficacy were similar across the two groups, $z$ $=-.53, p=.599$ (two-tailed). In contrast, the negative partial correlation between training and school-engagement problems $(r=-.17)$ for the Chinese American participants

\footnotetext{
${ }^{1,2}$ One-tailed tests were used for these analyses because their alternative hypotheses involved a specific direction. For note 1, the two alternative hypotheses are that the perceived levels of training are higher than 2 for the European and the Chinese American participants. For note 2, the alternative hypothesis is that the partial correlation between training and school-engagement problems for the Chinese American participants is smaller than the partial correlation between the two variables for their European American counterparts.
} 
was significantly smaller than the coefficient of the partial correlation between the two variables $(r=.03)$ for their European American counterparts, $z=-1.77, p=.038$, one-tailed. ${ }^{2}$ This finding suggests that training was linked with fewer school-engagement problems for the Chinese American adolescents than for their European American peers.

\section{Discussion}

This study examines perceptions of training parenting and its relations with adolescent outcomes among academically gifted European and Chinese American students. Contrary to our hypotheses, we found more similarities than differences between the two groups. Our findings show that students in the two groups perceived that their parents used similarly high levels of training. We also found that training was a positive predictor of academic efficacy for the two groups at similar levels, and we found no association between training and psychological adjustment for either group. However, one difference emerged: Our data indicate no correlation between training and school-engagement problems for the European American participants, but a negative correlation for their Chinese American peers. Our findings suggest that training parenting is a common approach used by both European and Chinese American parents of academically gifted students. However, the study suggests that there are ethnic differences as well as ethnic similarities in its implications for adolescent adjustment in our sample: The positive implication of training may be associated with both academic and school adjustment (particularly in terms of academic efficacy and school engagement) for the Chinese American adolescents but only with academic adjustment (again, particularly in terms of academic efficacy) for the European American adolescents.

One key ethnic similarity identified in our study is that the academically gifted European and Chinese American adolescents perceived similarly high levels of training, suggesting that training is an approach shared by parents of academically gifted students from both ethnicities. The following reasoning likely explains this finding. Academic success is highly valued by the parents of academically gifted students across ethnic groups [37]. Moreover, Chao [1, 27] observed that for Chinese parents, the purpose behind training is to educate children to meet societal and parental expectations, such as educational success. Extending this view, our finding suggests that training may have a similar purpose for both European and Chinese American parents.

Another important ethnic similarity concerns the implications of training for adolescent academic adjustment. Specifically, our findings indicate that training was a positive predictor of academic efficacy for both the European and the Chinese American adolescents. Training, which aims to help children achieve academic success, is especially beneficial for Chinese children's academic adjustment [1, 27]. Again, since we focused on a group of academically gifted students, and academic efficacy and success are highly valued by such students [37], the parenting approach that aims to foster academic success may also be valued by the academically gifted European American students and thus have positive implications for their academic adjustment.

The implications of training for adolescent psychological adjustment were also similar for both groups. Specifically, no significant association was noted between training and depression or anxiety for either group, suggesting that in both groups, training is not beneficial for the psychological adjustment of academically gifted students. This finding supports previous findings about regular European American and ethnic Chinese students, including samples of mainland Chinese and European American college students [3] and European and Chinese American children [28]. Accordingly, the absence of positive implications of training for children's psychological adjustment may be similar for immigrant and non-immigrant Chinese as well as European American students of different ages and different levels of academic giftedness. Such an absence is likely explained by the nature of training (i.e., an approach to promoting children's educational success rather than their psychological well-being)[1].

Despite these similarities, one critical difference emerged: We found a positive association between training and fewer school-engagement problems (specifically, fewer problems in getting along with teachers/peers and paying attention in class) for the academically gifted Chinese American adolescents, but no association for their European American peers. This ethnic difference suggests that training may play a more important role in having positive implications for academically gifted Chinese American adolescents' school engagement. The following reasoning may explain the ethnic difference. Chinese culture in general emphasizes the importance of teaching children to be obedient, and it is the parents' responsibility to discipline their children [26]. Training has been described as a Chinese parenting approach to this parenting responsibility $[1,27]$. Thus, when the Chinese American adolescents in our sample experience training parenting, they may perceive the positive connotation behind the parenting (e.g., my parents are taking on their responsibility to discipline me), so that this parenting has a positive implication for their school engagement. In contrast, because European American families place a greater emphasis on fostering children's autonomy rather than obedience [8], the European American adolescents in our sample may perceive training as a way to hinder their autonomy development, and thus this parenting approach does not have positive implications for their school engagement. There is a need for future research to provide evidence for this possibility through a qualitative study, such as interviewing both European and Chinese American adolescents about their perceptions of the meaning of training. 


\subsection{Limitations}

We acknowledge a number of limitations. First, our study draws on cross-sectional data. Longitudinal data may provide more compelling evidence regarding causal effects of training in European and Chinese American families. Second, it relies solely on student report data. While some research has found high levels of consistency between adolescent and parent report data in family dynamics [41], future research will benefit from incorporating parental report data. Third, our student report data measure perceptions of training by both mothers and fathers, without distinguishing between the two. This may overlook potential gender differences in parenting in families with academically gifted students. Future research will benefit from assessing these students' perceptions of paternal and maternal training separately.

Fourth, the approach to identifying academically gifted students in the school where the sample was recruited utilized a single test score to screen and choose academically talented students. McClain and Pfeiffer [9] have noted that the single-test method has one potential shortcoming. That is, it has the likelihood of excluding those populations of academically gifted children whose performance on a particular test for some reason does not reach a cutoff score for "gifted" identification (e.g., physically or psychologically, they did not function well on the test day). Accordingly, caution is warranted in interpreting our findings, since they might not be generalizable to other academically talented groups who are screened by other methods (e.g., utilizing multiple test scores).

Fifth, a marked ethnic difference in SES (lunch status) was noted: Very few of the European American students qualified for a free or reduced-price lunch, while approximately half of the Chinese American students qualified. To partial out the possibility that the ethnic difference was confounded by the SES difference, lunch status was controlled for all of the analyses comparing the two ethnic groups in terms of perceived levels of training and the relations between training and all of the adolescent outcome variables. However, it is still possible that there are interaction effects of ethnicity and SES on training and its relations with adolescent outcomes. This study could not test this second possibility due to the low variability in lunch status in the European American sample. Future research will benefit from sampling both European and Chinese American academically gifted students with diverse SES backgrounds.

\subsection{Contributions}

Our study makes three major contributions to current cross-cultural research on parenting and adolescent development. First, our findings suggest that there is more fluidity and complexity in parenting than is currently understood in scholarly research [7]. For example, Chinese concepts of parenting such as training may also exist in some European American families. It is important for future research to continue unpacking both similarities and differences in parenting goals and approaches across cultures. In particular, we believe it is important to avoid approaches that pit different parenting approaches/styles against each other through polarized concepts. Second, our study found that cross-ethnic similarities prevailed over potential differences in the approach to parenting and its implications for adolescent development, particularly regarding academic and psychological adjustment, in families of academically gifted students. The similarities suggest that there may be some common family dynamics in these families. In the future, it is important to continue examining the common and unique family dynamics of academically gifted students across ethnicities. Third, although academically gifted students are generally perceived as being homogeneously well-adjusted in all areas, some research has indicated marked variations in their adjustment outcomes (e.g., [12, 13]). Our findings lend support to this view. Moreover, our study suggests that training is an important factor that can explain the variations in their adjustment outcomes, at least for academic and school adjustment. For example, in our sample, training predicted better academic efficacy and school engagement for the academically gifted Chinese American adolescents and only better academic efficacy for their European American peers.

\subsection{Implications}

Our findings suggest several implications. It is important for Chinese American parents of academically gifted adolescents to know that although training parenting may be a positive parenting approach for their adolescents' academic adjustment and school engagement, it may not have positive implications for other developmental arenas, at least regarding psychological adjustment. To promote their adolescents' psychological well-being, they can integrate training with other parenting approaches, such as parental warmth, which has been identified as beneficial for academically gifted students' psychological health [13]. A similar suggestion is provided for European American parents of academically gifted adolescents. Given that training predicted only better academic efficacy for the European American sample, these European American parents can also incorporate other approaches, such as parental warmth, into their parenting to foster their adolescents' psychological adjustment. To promote greater school engagement, these European American parents can exercise authoritative parenting, which has been described as beneficial for academically gifted students' school engagement [16].

\section{Conclusions}

The present study highlights that similarities prevailed 
over differences in the approach to parenting and its implications for adolescent development, in European and Chinese American families of academically gifted students. Specifically, our findings suggest that training parenting is a common approach used by both European and Chinese American parents of academically gifted students. In addition, the findings suggest that training has positive implications for academic adjustment (particularly in terms of academic efficacy) among both academically gifted European and Chinese American adolescents. However, one ethnic difference emerges: the positive implication of training for school adjustment (particularly in terms of school engagement) was found only among academically gifted Chinese American adolescents.

We acknowledge one future direction. This study only examined training parenting and one academic outcome (i.e., academic efficacy) of academically gifted European and Chinese American adolescents. Future research would benefit from using a similar research design with diverse ethnic groups, with regular students, and with various academic outcomes as well as testing relations between training and other parenting approaches/styles (e.g., authoritative parenting) and comparing the implications of training with the implications of other parenting approaches/styles. Doing so would provide the following useful information: 1) whether training parenting and its salient characteristics (i.e., using continuous control to educate children to achieve societal and parental expectations and conveying parental nurturance through parents' instrumental support for children's education and behavior) are commonly adopted by parents across ethnicities and parents of both regular and academically gifted adolescents; 2) how training is related to other parenting approaches/styles (e.g., authoritative and authoritarian parenting); and 3) whether training is optimal for overall academic adjustment across ethnic groups and adolescents with different levels of academic giftedness. Moreover, the findings of the research direction would improve our understanding of whether training may be advocated for being adopted by parents across ethnic groups and of both regular and academically gifted adolescents, particularly if the parents would like to promote good academic adjustment of their children.

\section{REFERENCES}

[1] R. K. Chao. Beyond parental control and authoritarian parenting style: Understanding Chinese parenting through the cultural notion of training, Child Development, vol. 65, no. 4, pp. 1111-1119, 1994.

[2] A. Chua. Battle Hymn of the Tiger Mother, Penguin Press, New York, NY, USA, 2011.

[3] Y. Li, P. R. Costanzo, M. Putallaz. Maternal socialization goals, parenting styles, and social-emotional adjustment among Chinese and European American young adults: Testing a mediation model, The Journal of Genetic Psychology, vol. 171, no. 4, pp. 330-362, 2010.

[4] R. K. Chao. Extending research on the consequences of parenting style for Chinese Americans and European Americans, Child Development, vol. 72, no.6, pp. 1832-1843, 2001.

[5] E. Pearson, N. Rao. Socialization goals, parenting practices, and peer competence in Chinese and English preschoolers, Early Child Development \& Care, vol. 173, pp. 131-146, 2003.

[6] V.S.Y. Kwan, M.H. Bond, T.M. Singelis, Pancultural explanations for life satisfaction: Adding relationship harmony to self-esteem, Journal of Personality and Social Psychology, vol. 73, no.1, pp. 1038-1051, 1997.

[7] C. S. Tamis-LeMonda, N. Way, D. Hughes, H. Yoshikawa, R. K. Kalman, E. Y. Niwa. Parents' goals for children: The dynamic coexistence of individualism and collectivism in cultures and individuals, Social Development, vol. 17, no.1, pp. 183-209, 2008

[8] F. Rothbaum, G. Trommsdorff. Do roots and wings complement or oppose one another: The socialization of relatedness and autonomy in cultural context. In: J. Grusec and P. Hastings (Eds.) Handbook of socialization, 2nd ed., pp. 461-489, Guilford Press, New York, NY, USA, 2007.

[9] M. C. McClain, S. Pfeiffer. Identification of gifted students in the United States today: A look at state definitions, policies, and practices. Journal of Applied School Psychology, vol. 28, no.1, pp. 59-88, 2012.

[10] J. D. McLeod, R. Uemura, S. Rohrman. Adolescent mental health, behavior problems, and academic achievement, Journal of Health and Social Behavior, vol. 53, no. 4, pp. 482497, 2012.

[11] B. J. Zimmerman. Self-efficacy and educational development, In A. Bandura (Ed.) Self-efficacy in changing societies, pp. 202-231, Cambridge University Press, New York, NY, USA, 1995.

[12] T-F. Chang, B. D. Qin. Relations between academic adjustment and parental psychological control of academically gifted Chinese American and European American students, Child Indicators Research, Advance online publication, DOI: 10.1007/s12187-016-9403-1, 2016.

[13] L. D. Feld, A. Shusterman. Into the pressure cooker: Student stress in college preparatory high schools, Journal of Adolescence, vol. 41, pp. 31-42, 2015.

[14] D. B. McCoach, D. Siegle. Factors that differentiate underachieving gifted students from high-achieving gifted students, Gifted Child Quarterly, vol. 47, no. 2, pp. 144-154, 2003.

[15] S. M. Reis, D. B. McCoach. The underachievement of gifted students: What do we know and where do we go? Gifted Child Quarterly, vol. 44, no. 3, pp. 152-170, 2000.

[16] R. D. Taylor. Risk and resilience: Contextual influences on the development of African American adolescents, In: M. C. Wang and E. W. Gordon (Eds.) Educational resilience in inner city America, pp. 119-137, Lawrence Erlbaum, Hillsdale, NJ, USA, 1994. 
[17] D. Baumrind. Current patterns of parental authority, Developmental Psychology Monographs, vol. 2, no. 4, pp. 1-103, 1971.

[18] K. M. Rudasill, J. L. Adelson, C. M. Callahan, D. V. Houlihan, B. M. Keizer. Gifted students' perceptions of parenting styles: Associations with cognitive ability, sex, race, and age, Gifted Child Quarterly, vol. 57, no. 1, pp. 15-24, 2013.

[19] A. J. Supple, S. A. Small. The influence of parental support, knowledge, and authoritative parenting on Hmong and European American adolescent development, Journal of Family Issues, vol. 27, no. 9, pp. 1214-1232, 2006.

[20] K. L. S. Neumeister, H. Finch. Perfectionism in high-ability students: Relational precursors and influences on achievement motivation, Gifted Child Quarterly, vol. 50, no. 3, pp. 238-251, 2006.

[21] L. Steinberg, S. D. Lamborn, S. M. Dornbusch, N. Darling. Impact of parenting practices on adolescent achievement: Authoritative parenting, school involvement, and encouragement to succeed, Child Development, vol. 63, no. 5, pp. 1266-1281, 1992.

[22] X. Chen, Q. Dong, H. Zhou. Authoritative and authoritarian parenting practices and social and school performance in Chinese children, International Journal of Behavioral Development, vol. 21, no. 4, pp. 855-873, 1997.

[23] S. Pong, J. Johnston, V. Chen. Authoritarian Parenting and Asian Adolescent School Performance: Insights from the US and Taiwan, International Journal of Behavioral Development, vol. 34 , no. 1 , pp. $62-72,2010$.

[24] K. Leung, S. Lau, W. L. Lam. Parenting styles and academic achievement: A cross-cultural study, Merrill-Palmer Quarterly, vol. 44, pp. 157-172, 1998.

[25] Y. C. Wang. Assessing the reliability and validity of the survey measures of Guan, Jiao, and Xiao: Beyond Wang and Supple (2010), Marriage \& Family Review, vol. 52, no. 3, pp. 305-329, 2016

[26] M. H. Bond, K. K. Hwang. The social psychology of Chinese people. In: M. H. Bond (Ed.) The psychology of the Chinese people, pp. 213-264, Oxford University Press, Hong Kong, 1986.

[27] R. K. Chao. The parenting of immigrant Chinese and European American mothers relations between parenting styles, socialization goals, and parental practices, Journal of Applied Developmental Psychology, vol. 21, no. 2, pp. 233-248, 2000.

[28] C. S. Huntsinger, P. E. Jose. Relations among parental acceptance and control and children's social adjustment in Chinese American and European American families, Journal of Family Psychology, vol. 23, no. 3, pp.321-330, 2009.

[29] R. K. Chao, V. Tseng. Parenting of Asians. In M. H. Bornstein (Ed.) Handbook of Parenting, vol. 4, 2nd ed., pp.59-93, Erlbaum, Mahwah, NJ, USA, 2002.

[30] P. E. Jose, C. S. Huntsinger, P. R. Huntsinger, F.-R. Liaw. Parental values and practices relevant to young children's social development in Taiwan and the United States, Journal of Cross-Cultural Psychology, vol. 31, no. 6, pp. 677-702, 2000.

[31] A. R. Gonzalez, M. F. D. Holbein, S. Quilter. High school students' goal orientations and their relationship to perceived parenting styles, Contemporary Educational Psychology, vol. 27, no. 3, pp. 450-470, 2002.

[32] B. F. Piko, M. Á. Balázs. Authoritative parenting style and adolescent smoking and drinking, Addictive Behaviors, vol. 37, no. 3, pp. 353-356, 2012.

[33] W. S. G. Kwan, M. T. Leung. Perceived Chinese parenting beliefs and styles as antecedents on Hong Kong undergraduates' learning and achievement with self-other achievement motives as mediator. In: Applied Psychology: Proceedings of the 2015 Asian Congress of Applied Psychology (ACAP 2015), pp. 178-194, World Scientific, 2015.

[34] C. McBride-Chang, L. Chang. Adolescent-parent relations in Hong Kong: Parenting styles, emotional autonomy, and school achievement, The Journal of Genetic Psychology, vol. 159, no. 4, pp. 421-436, 1998.

[35] Y. C. Wang, A. J. Supple. Parenting behaviors and adolescent psychosocial adjustment in China: An indigenous perspective, Marriage \& Family Review, vol. 46, pp. 480497, 2010 .

[36] S. M. Stewart, M. H. Bond, B. D. Kennard, L. M. Ho, R. M. Zaman. Does the Chinese construct of guan export to the West? International Journal of Psychology, vol. 37, no. 2, pp. 74-82, 2002.

[37] S. Phillipson. Parental expectations. In: S. Phillipson, K. Y. L. $\mathrm{Ku}$, and S. N. Phillipson (Eds.) Constructing educational achievement: A sociocultural perspective, pp.87-104, Routledge, Abingdon, England, 2013.

[38] S. Krane. New York City Specialized Science High Schools Admission Test, ARCO, 2001.

[39] L. Muthén, B. Muthén. Mplus: Statistical analyses with latent variables. User's guide, Muthén \& Muthén, Los Angeles, CA, USA, 1998-2012.

[40] F. F. Chen, K. H. Sousa, S. G. West. Testing measurement invariance of second-order factor models, Structural Equation Modeling: A Multidisciplinary Journal, vol. 12, no. 3, pp. 471-492, 2005.

[41] I. J. K. Park, J. Garber, J. A. Ciesla, B. J. Ellis. Convergence among multiple methods of measuring positivity and negativity in the family environment: Relation to depression in mothers and their children, Journal of Family Psychology, vol. 22, no.1, pp. 123-134, 2008.

[42] R. J. Gregory. Psychological testing: history, principles, and applications, $4^{\text {th }}$ ed., Pearson, Boston, MA, USA, 2004.

[43] J. E. Helms, K. T. Henze, T. L. Sass, S. Mifsed. Treating Chronbach's alpha reliability coefficients as data in counseling research, The Counseling Psychologist, vol. 34, no. 5, pp. 630-660, 2006.

[44] J. C. Nunnally. Psychometric theory, 2nd ed., McGraw-Hill, New York, NY, USA, 1978.

[45] M. Kovacs. Children's Depression Inventory. Multi-Health Systems, Inc, North Tonawanda, NY, USA, 1992.

[46] D. R. Crane, S. W. Ngai, J. H. Larson, M. Hafen. The Influence of Family Functioning and Parent-Adolescent Acculturation on North American Chinese Adolescent Outcomes, Family Relations, vol. 54, no. 3, pp. 400-410, 2005 . 
[47] S. D. Simpkins, J. S. Eccles, J. N. Becnel. The mediational role of adolescents' friends in relations between activity breadth and adjustment, Developmental Psychology, vol. 44 no. 4, 1081-1094, 2008 .

[48] C. R. Reynolds, B. O. Richmond. What I think and feel: A revised measure of children's Manifest Anxiety, Journal of Abnormal Child Psychology, vol. 6, pp. 271 - 280, 1978

[49] L. C. Dierker, A. M. Albano, G. N., Clarke, R. G. et al. Screening for anxiety and depression in early adolescence, Journal of the American Academy of Child \& Adolescent Psychiatry, vol. 40, no. 8, pp. 929-936, 2001.

[50] Q. Dong, B. Yang, T. H. Ollendick. Fears in Chinese children and adolescents and their relations to anxiety and depression, Journal of Child Psychology and Psychiatry, vol. 35, no. 2, pp. 351-363, 1994

[51] ] K.M. Harris, E. Halpern, J. Whitsel et al. The National Longitudinal Study of Adolescent Health: Research design [WWW document], URL: http://www.cpc.unc.edu/projects/addhealth/design, 2009.

[52] C. A. McNeely, J. M. Nonnemaker, R. W. Blum. Promoting school connectedness: Evidence from the national longitudinal study of adolescent health, Journal of School Health, vol. 72, no. 4, pp. 138-146, 2002.

[53] Y. Mo, K. Singh. Parents' relationships and involvement: Effects on students' school engagement and performance, RMLE Online, vol. 31, no. 10, pp. 1-11, 2008.

[54] S. Huck. Reading statistics and research, $4^{\text {th }}$ ed., Allyn \& Bacon, Boston, USA, 2004

[55] P. D. Allison. Imputation of categorical variables with PROC MI, SAS Users Group International, 30th Meeting (SUGI 30), Philadelphia, PA, 2005.

[56] H. Aguinis, C. A. Pierce, E. F. Stone-Romero. Estimating the power to detect dichotomous moderators with moderated multiple regression, Educational and Psychological Measurement, vol. 54, no. 3, pp. 690-692, 1994.

[57] M. S. Bartlett. Properties of sufficiency and statistical tests. Proceedings of the Royal Society, A160, pp. 268-282, 1937.

[58] D. Hooper, J. Coughlan, M. Mullen. Structural equation modelling: Guidelines for determining model fit, Electronic Journal of Business Research Methods, vol. 6, no. 1, pp. 53-60, 2008. 